\title{
Treatment of muscle-invasive bladder cancer in Canada: A survey of genitourinary medical oncologists and urologists
}

\author{
Tina Hsu, MD, FRCPC; ${ }^{*}$ Peter C. Black, MD, FACS, FRCSC; ${ }^{\dagger}$ Kim N. Chi, MD, FRCPC; Christina M. Canil, MD, \\ FRCPC,: Bernhard J. Eigl, MD, FRCPC,; Girish Kulkarni, MD, PhD, FRCSC;, Scott North, MD, FRCPC;; \\ Lori Wood, MD, FRCPC,; Alexandre R. Zlotta, MD, PhD, FRCSC;, Anthea Lau,f Tony Panzarella, MSc, Pstat; \\ Srikala S. Sridhar, MD, MSc, FRCPC ${ }^{ \pm}$
}

*University of Toronto, Toronto ON; †University of British Columbia, Vancouver BC; §British Columbia Cancer Agency, Vancouver BC; ${ }^{ \pm 0 t t a w a ~ R e g i o n a l ~ C a n c e r ~ C e n t r e, ~ O t t a w a ~ O N ; ~}{ }^{*}$ Cross Cancer Institute, Edmonton AB; \#Queen Elizabeth II Health Sciences Centre, Halifax NS; EPrincess Margaret Cancer Centre, Toronto ON

Cite as: Can Urol Assoc J 2014;8(9-10):309-16. http://dx.doi.org/10.5489/cuaj.2111

Published online October 13, 2014.

\section{Abstract}

Introduction: Uptake of neoadjuvant chemotherapy (NC) for muscle invasive bladder cancer (MIBC) has been low despite evidence of a survival benefit. The primary aim of this study was to better understand why the rates are low and determine what factors specifically influence the decision to recommend NC for MIBC.

Methods: A 31-question survey was emailed between 2009 and 2011 to medical oncologists belonging to the Canadian Association of Genitourinary Medical Oncologists (CAGMO); and to urologists belonging to the Canadian Urologic Oncology Group (CUOG). We gathered data on practice characteristics, referrals for $\mathrm{NC}$, factors influencing NC use, and chemotherapy regimens offered. Responses were summarized using descriptive statistics.

Results: In total, 26/30 (87\%) medical oncologists and 25/84 $(30 \%)$ urologists, who were primarily academic, completed the survey. Most clinicians (medical oncologists $96 \%$, urologists $88 \%$ ) recommended $\mathrm{NC}$ for $\mathrm{MIBC}$, because they considered it to be the standard of care, but most medical oncologists saw $\leq 6$ referrals annually. Performance status, presence of comorbidities and renal function were key considerations in offering NC. NC was not offered if performance status $\geq 2$ (medical oncologists 38\%, urologists $44 \%$ ), age $>80$ (medical oncologists $46 \%$, urologists $39 \%$ ), or glomerular filtration rate $\leq 40 \mathrm{~mL} / \mathrm{min}$ (medical oncologists $81 \%$, urologists $50 \%$ ).

Conclusions: Most academic clinicians in Canada believe that cisplatin-based combination NC is the standard of care for MIBC and recommend it for patients with adequate performance status and renal function. Using a multidisciplinary approach to treat this disease may be one strategy to increase referral rates for $\mathrm{NC}$ and uptake of NC.

\section{Introduction}

According to the Canadian Cancer Society, bladder cancer is the fifth most common cancer overall, accounting for 7800 cases/year; of these cases, about $15 \%$ to $20 \%$ are muscle invasive bladder cancers (MIBC). ${ }^{1}$ For these patients, radical cystectomy arguably remains the standard of care. However, 5 -year overall survival rates following radical cystectomy alone are only $50 \%$, and fall to $37 \%$ and $31 \%$ in patients with extravesical extension and lymph node involvement, respectively. ${ }^{2,3}$ Recurrences often occur distantly, suggesting the presence of micrometastatic disease at the time of surgery. Attempts to improve outcomes have therefore focused on the use of neoadjuvant cisplatin-based combination chemotherapy to improve overall survival. ${ }^{4}$

In the MRC/EORTC (Medical Research Council/European Organization for Research and Treatment of Cancer) trial, 976 patients were randomized to 3 cycles of cisplatin, methotrexate and vinblastine or no neoadjuvant chemotherapy (NC) followed by cystectomy or radiation. NC had an absolute survival benefit of $5 \%$ and a relative risk reduction in death of $16 \%$ at 10 years. ${ }^{5}$ Similarly, the SWOG 8710 trial which randomized 317 MIBC patients to 3 cycles of methotrexate, vinblastine, doxorubicin, cisplatin (MVAC) followed by cystectomy or cystectomy alone, showed a median survival of 77 months with NC versus 46 months without NC; and a 5 -year overall survival of $57 \%$ versus $43 \%(p=0.06){ }^{6}$ Furthermore, a meta-analysis of 3005 patients from 11 randomized trials has also shown a $5 \%$ absolute overall survival benefit at 5 years ( $50 \%$ vs. $45 \%$ ) with cisplatin-based combination NC. ${ }^{4}$

Despite this Level 1 evidence, NC uptake has historically been low. ${ }^{7}$ However, recent studies suggest NC uptake may be increasing. An American study of 5692 patients treated from 2006 to 2010 showed a NC rate of $10.1 \%$ in 
Hsu et al.

a) All referrals

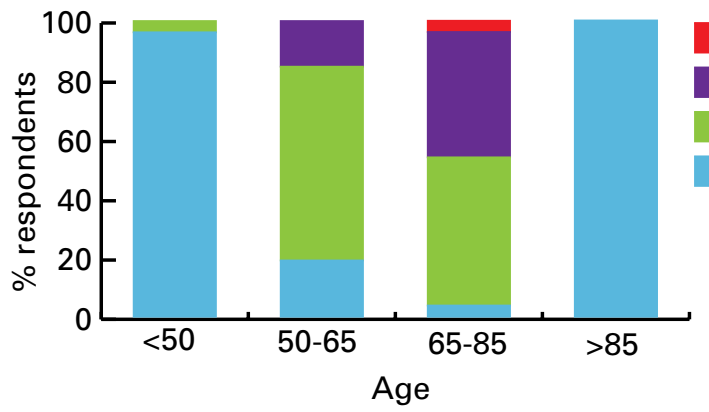

c) All referrals

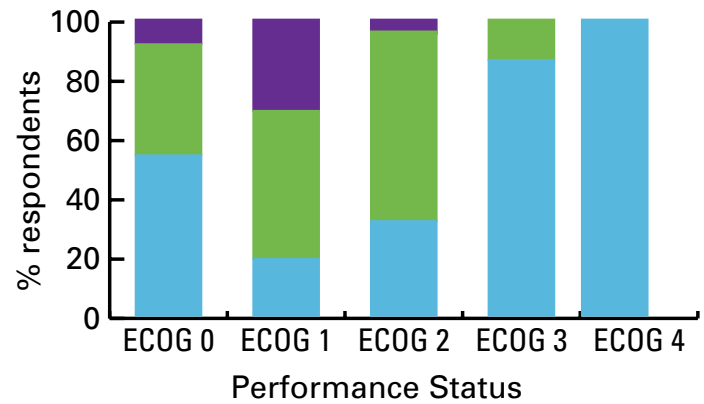

b) Neoadjuvant referrals

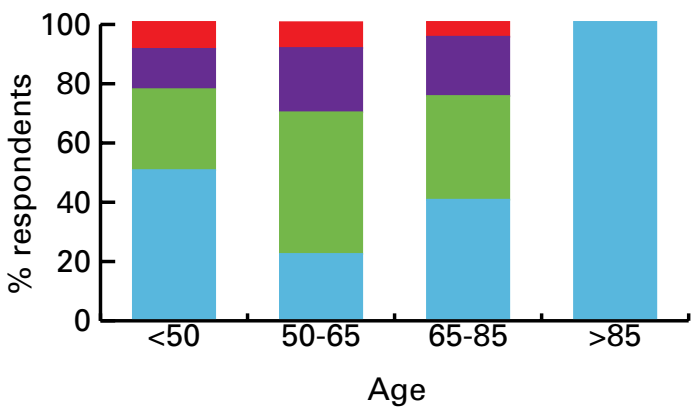

d) Neoadjuvant referrals

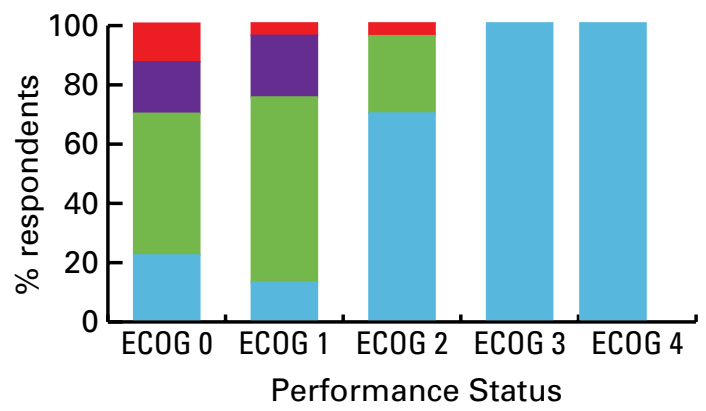

Fig. 1. Age and performance status of new bladder cancer referrals received by medical oncologists (left - all bladder cancer referrals, right - referrals for neoadjuvant chemotherapy). ECOG: Eastern Cooperative Oncology Group.

2006, which increased to $20.8 \%$ by $2010 .{ }^{8}$ Similarly, an Australian study showed an uptake of $17 \%$ increasing over time. ${ }^{9}$ Nonetheless, in the context of Level 1 evidence, these rates are low, and these retrospective studies do not help us understand why.

The primary aim of this study was to better understand why uptake is low and determine what factors influence the decision to recommend NC by surveying medical oncologists and urologists.

\section{Methods}

A 31-question survey covering 5 domains (practice characteristics; referrals for bladder cancer and NC; reasons to not offer NC; chemotherapy used) was developed. Five medical oncologists reviewed questions to ensure content and face validity and feedback was incorporated into the final survey (Appendix 1; http://journals.sfu.ca/cuaj/index.php/journal/ article/view/2111). The survey was sent electronically to medical oncologists, belonging to the Canadian Association of Genitourinary Medical Oncologists (CAGMO), and to urologists (excluding chemotherapy-specific questions) belonging to the Canadian Urologic Oncology Group
(CUOG). Both groups were contacted several times to enhance the response rate. Respondents completing the survey voluntarily gave implied consent, so formal consent forms were not required.

Responses were summarized using proportions and percentages. All percentages were calculated as a function of the number of respondents for each question.

\section{Results}

\section{Respondent characteristics}

The response rate for medical oncologists was $87 \%$ (26/30): $92 \%$ were academic, $42 \%$ focused primarily on GU cancers (Table 1). The response rate for urologists was 30\% (25/84): $84 \%$ were academic, $72 \%$ focused primarily on genitourinary (GU) cancers.

\section{Referrals}

Most medical oncologists (88\%) and urologists (63\%) referred $\leq 6$ cases/year for $\mathrm{NC}$, though some urologists 
a) All referrals

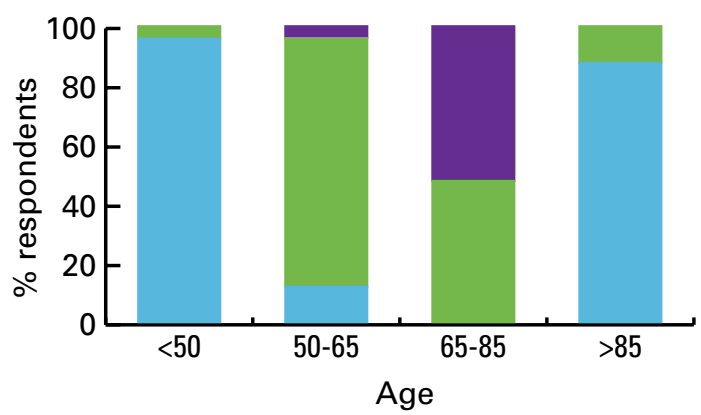

c) All referrals

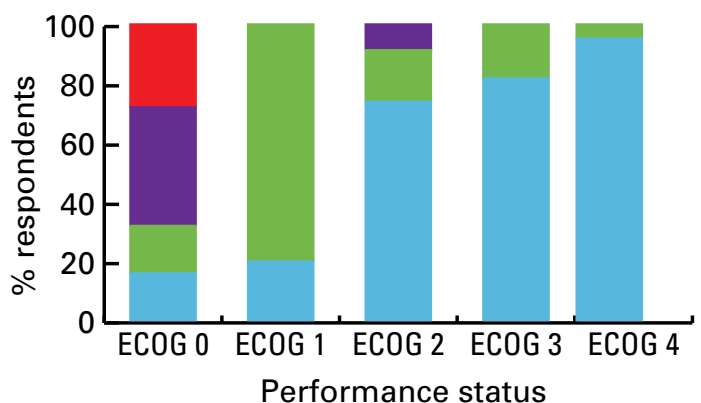

b) Neoadjuvant referrals

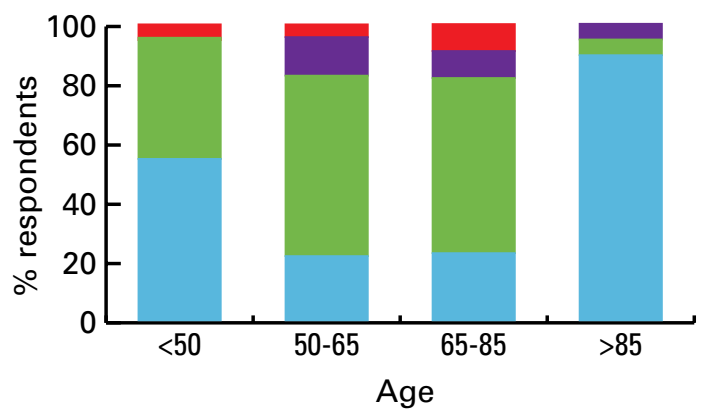

d) Neoadjuvant referrals

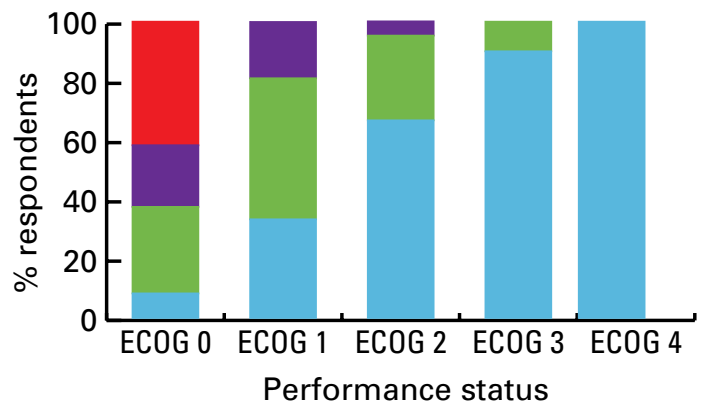

Fig. 2. Age and performance status of new bladder cancer referrals made by urologists (left - all bladder cancer referrals, right - referrals for neoadjuvant chemotherapy). ECOG: Eastern Cooperative Oncology Group.

referred more frequently ( $8 \%$ referred 10 cases/year; $8 \%$ referred 15 cases/year; and $8 \%$ at $\geq 20$ cases/year). The highest referral rates occurred in the setting of a multidisciplinary clinic and/or care pathway (Table 1 ).

We illustrated the age and performance status of all referrals and referrals for $\mathrm{NC}$ as reported by medical oncologists (Fig. 1) and urologists (Fig. 2). Younger patients (especially
$<50$ ) and patients with better performance status were more commonly referred for NC. Patients with T2a tumours were never/rarely offered NC (medical oncologists 48\% never; urologists $40 \%$ never); compared to patients with T3b disease (Fig. 3).

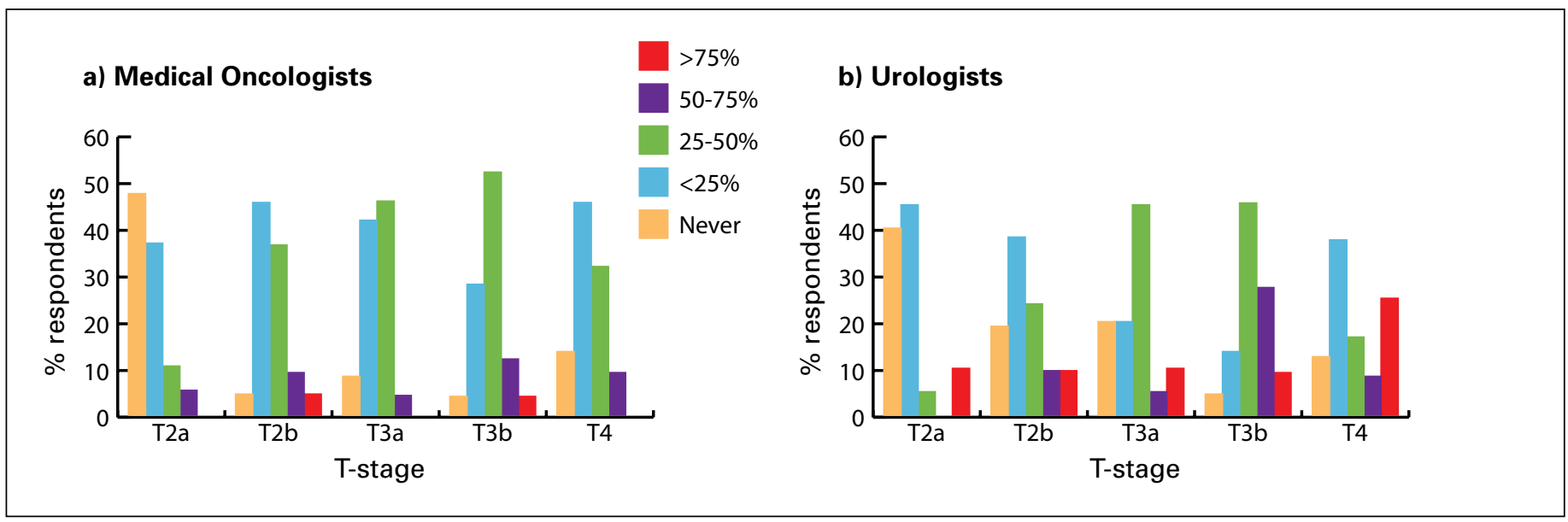

Fig. 3. Referrals for neoadjuvant chemotherapy by T-stage as reported by (a) medical oncologists (b) and urologists. 
Hsu et al.

\begin{tabular}{|c|c|c|}
\hline & $\begin{array}{c}\text { Medical } \\
\text { oncologists } \\
(n=26), \text { no. }(\%)\end{array}$ & $\begin{array}{c}\text { Urologists } \\
(n=25), \text { no. }(\%)\end{array}$ \\
\hline Academic & $24(92.3)$ & $21(84.0)$ \\
\hline $\begin{array}{l}\text { Time in clin } \\
25-50 \% \\
50-75 \% \\
>75 \%\end{array}$ & $\begin{array}{c}6(23.1) \\
15(57.7) \\
5(19.2)\end{array}$ & $\begin{array}{c}2(8.0) \\
10(40.0) \\
13(52.0)\end{array}$ \\
\hline $\begin{array}{l}\text { Years in pra } \\
<5 \text { years } \\
5-9 \text { years } \\
\geq 10 \text { years }\end{array}$ & $\begin{array}{c}5(19.2) \\
7(26.9) \\
14(53.8)\end{array}$ & $\begin{array}{c}3(12.0) \\
4(16.0) \\
18(72.0)\end{array}$ \\
\hline 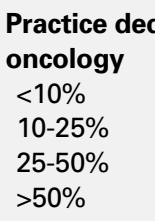 & $\begin{array}{c}1(3.8) \\
8(30.8) \\
6(23.1) \\
11(42.3)\end{array}$ & $\begin{array}{c}1(4.0) \\
4(16.0) \\
2(8.0) \\
18(72.0)\end{array}$ \\
\hline $\begin{array}{l}\text { Bladder can } \\
\text { (patients/ye } \\
5-10 \\
11-15 \\
16-20 \\
>20\end{array}$ & $\begin{array}{l}4(15.4) \\
10(38.5) \\
5(19.2) \\
7(26.9)\end{array}$ & $\begin{array}{c}0(0) \\
1(4.0) \\
3(12.0) \\
21(84.0)\end{array}$ \\
\hline \multicolumn{3}{|c|}{$\begin{array}{l}\text { Bladder cancer referrals for } \\
\text { neoadjuvant management } \\
\text { (patients/year) }\end{array}$} \\
\hline 0 & $0(0)$ & $2(8.3)$ \\
\hline $1-2$ & $8(32.0)$ & $5(20.3)$ \\
\hline $3-4$ & $7(28.0)$ & $6(25.0)$ \\
\hline $5-6$ & $7(28.0)$ & $2(8.3)$ \\
\hline$>6$ & $3(12.0)$ & 9 (37.5) \\
\hline Missing & 1 & 1 \\
\hline
\end{tabular}

\section{Goals of NC}

Most clinicians report offering NC, because they considered it to be the standard of care (medical oncologists $96 \%$, urologists $88 \%$ ) (Fig. 4).

\section{Factors influencing decision to use NC}

Figure 5 shows the relative importance of patient and tumour characteristics for medical oncologists and urologists. Figure 6 shows the threshold at which clinicians would not offer NC. Performance status was the most important factor - about $40 \%$ did not offer NC to patients with Eastern Cooperative Oncology Group (ECOG) performance status $\geq 2 .{ }^{10}$ Most medical oncologists $(81 \%)$ and urologists $(50 \%)$ report that they would not offer NC if glomerular filtration rate (GFR) was $\leq 20$ to $40 \mathrm{~mL} / \mathrm{min}$. Age was not a key factor, yet $46 \%$ of medical oncologists and $39 \%$ of urologists did not offer NC to patients who were $\geq 80$ years old. T-stage was not a major consideration for $39 \%$ of medical oncologists and $21 \%$ of urologists. NC was commonly offered to patients with T3 disease, but not offered to those with T2a disease (medical oncologists 31\%, urologists 46\%) (Fig. 6, part D).

\section{Chemotherapy regimens used}

All medical oncologists reported using gemcitabine/cisplatin (GC) neoadjuvantly. Other regimens included dose-dense methotrexate/vinblastine/adriamycin/cisplatin (MVAC) (19\%), gemcitabine/carboplatin (8\%), standard MVAC (4\%) and gemcitabine/cisplatin/paclitaxel (4\%). In the presence of renal insufficiency (GFR $<40-60 \mathrm{~mL} / \mathrm{min}$ ), $8 \%$ of medical oncologists split cisplatin over days 1 and $8,8 \%$ modified the dose, $21 \%$ substituted carboplatin for cisplatin, while $17 \%$ forewent NC altogether.

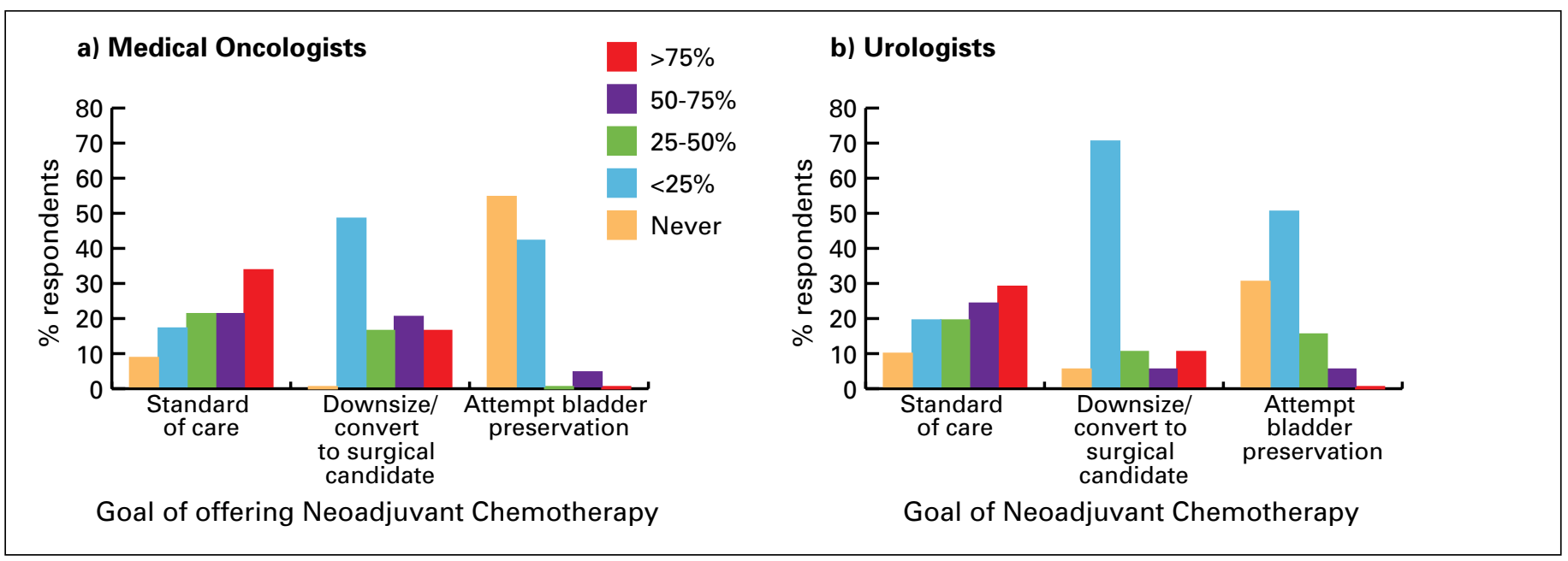

Fig. 4. Goals of neoadjuvant chemotherapy as reported by (a) medical oncologists and (b) urologists. 


\section{Barriers to NC}

Additional barriers to NC use included the belief that NC does not improve survival, concern that disease progression during NC could render patients incurable, and difficulty getting community medical oncologists to administer NC.

\section{Discussion}

Despite evidence demonstrating a survival benefit of $\mathrm{NC}$ in MIBC, uptake remains low. Understanding and addressing the reasons for low uptake may lead to higher rates of NC use and possibly improved outcomes.

In this survey of Canadian GU medical oncologists and urologists, most respondents were academic and practicing $\geq 10$ years. Overall, NC was offered by most respondents based mostly on the belief that $\mathrm{NC}$ is the standard of care for MIBC. However, $88 \%$ and $62.5 \%$ of medical oncologists and urologists, respectively, still reported seeing or referring $\leq 6$ patients/year for NC. Previous studies suggest that referral rates to a medical oncologist are generally low and may account for non-receipt of NC. ${ }^{11-13}$ Prior studies evaluating NC in MIBC suggest that the implementation of a standardized multidisciplinary approach increases the referral rate and the uptake of NC in eligible patients, even in the academic setting. ${ }^{11,13}$ Respondents who saw and referred the highest cases of NC annually reported doing so in the context of a multidisciplinary clinic.

Our results suggest that a multidisciplinary approach, which is not a new concept in oncology, may increase NC uptake. This approach may promote discussion between medical oncologists and urologists and provide patients with a balanced opinion of risks and benefits of NC upfront. Alternatively, it may be more feasible to automatically refer all patients with agreed upon characteristics (i.e., performance status $0-1$, limited comorbidities, and adequate renal function) for NC. Overall, we found general agreement between medical oncologists and urologists on characteristics of patients eligible for NC. In fact a consensus guideline, developed by Canadian medical oncologists and urologists, has suggested a streamlined multidisciplinary referral process to standardize treatment of MIBC and increase NC uptake. ${ }^{14}$

The discrepancy between willingness to administer NC and actual use may also reflect selective utilization of NC due to patient factors, such as poor performance status, presence of comorbidities and renal dysfunction, all of which are prevalent in this population and were key reasons for not recommending NC in other studies. ${ }^{15-17}$ Studies suggest that up to $33 \%$ to $47 \%$ of patients have renal dysfunction $(\mathrm{CrCl}<60 \mathrm{~mL} / \mathrm{min})$ preoperatively which may preclude NC. ${ }^{15,18}$ In our study, for patients with mild renal dysfunction, medical oncologists reported they may modify the chemotherapy dose, schedule or regimen, though the evidence supporting these approaches is less robust. Currently, it is unclear if it is better for patients with MIBC to receive modified cisplatin-based combination chemotherapy or forego NC altogether. Clearly, more studies are needed.

Although age was less important in our study, patients referred for $\mathrm{NC}$ tended to be younger. This is similar to other studies showing age $\geq 75$ precludes referral to a medical oncologist due to concerns over chemotherapy tolerability, a higher prevalence of comorbidities $(50 \%$ of those $\geq 75$ have more than 4 comorbidities) and renal dysfunction with increasing age. ${ }^{18,19}$ Admittedly there were few patients in their 70s and 80s included in prospective NC studies and as a result the data supporting its use in these patients are less robust., ${ }^{5,6}$ One study, however, suggested that toxicities were comparable in patients $\geq 70$ and $<70$ receiving NC. ${ }^{20}$

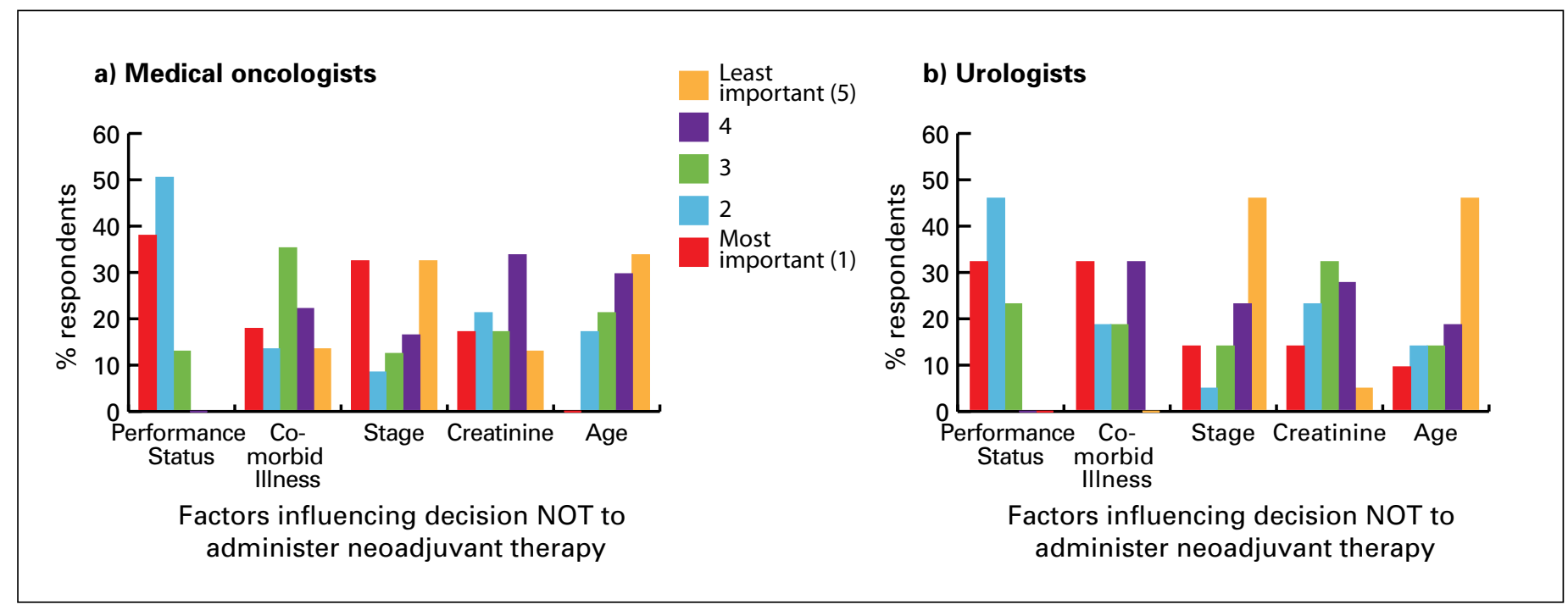

Fig. 5. Factors influencing decision not to administer neoadjuvant chemotherapy for (a) medical oncologists and (b) urologists. 
Hsu et al.

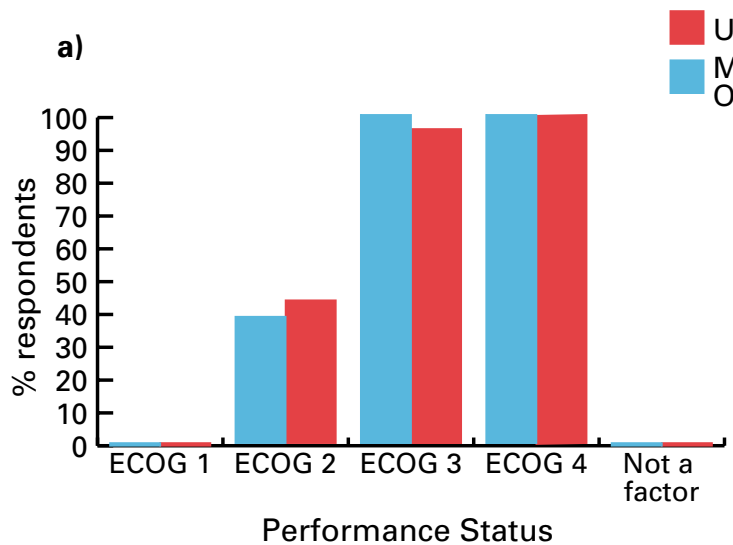

b)

Medical

Oncologists

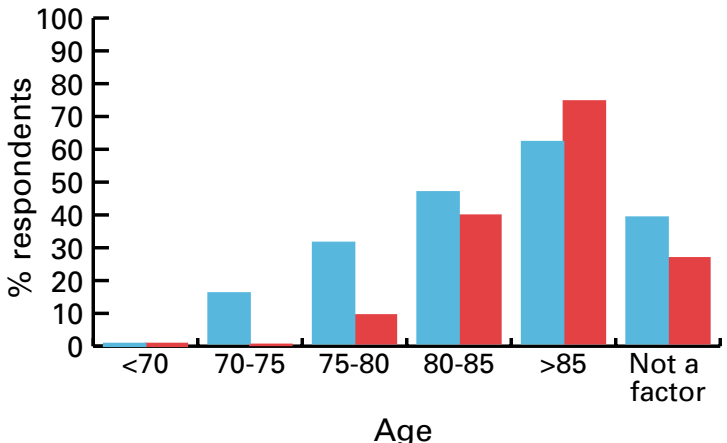

d)

c)
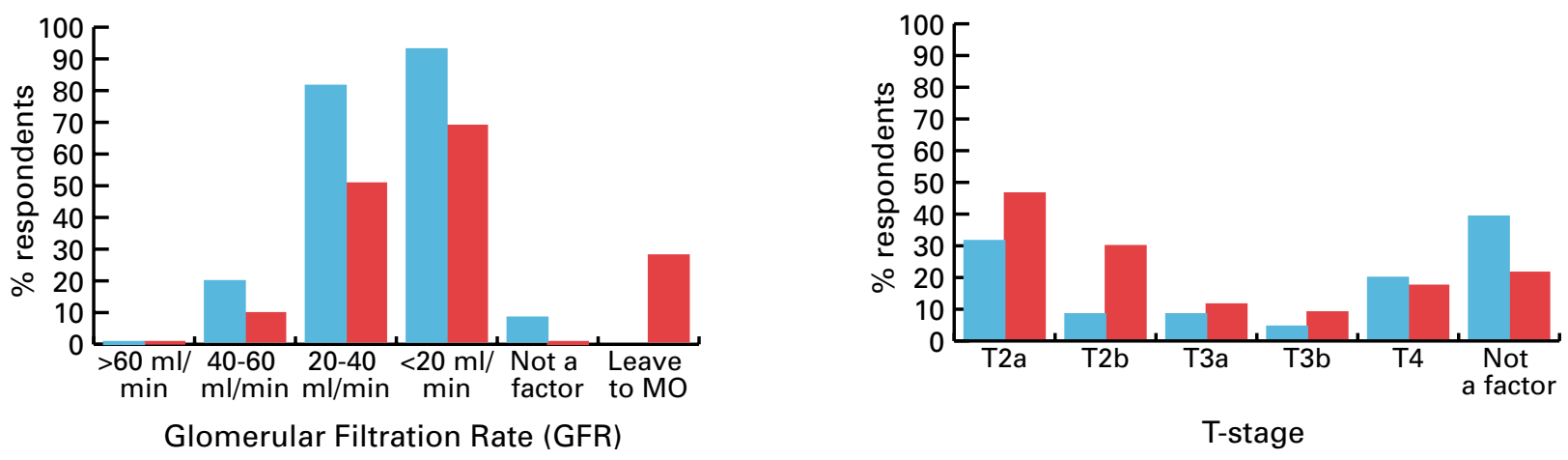

Fig. 6. Threshold at which medical oncologists and urologists would not offer neoadjuvant chemotherapy to patients by a) performance status, b) age, c) renal function, and d) T-stage. ECOG: Eastern Cooperative Oncology Group; MO: medical oncologist.

As the median age of bladder cancer patients is 73 and $>20 \%$ are over $80,,^{21-23}$ further studies in older adults and cisplatin-ineligible patients are clearly needed.

Tumour factors also play a role in decision-making. Although NC studies included patients with T2-T4a NO disease, our results suggest that many clinicians rarely offer $\mathrm{NC}$ to patients with T2-disease. This perhaps reflects a belief that these patients have a better prognosis and derive less relative benefit from $\mathrm{NC} .{ }^{24}$ Discrepancies between clinical and pathological staging is a major issue in MIBC with upstaging post-cystectomy occurring in almost $30 \%$ to $61 \%$ of cases. ${ }^{16,25-27}$ One of the strongest risk factors for upstaging is T2-disease. ${ }^{25-27}$ As $20 \%$ to $30 \%$ of patients with pT2 disease relapse distantly and the SWOG-8710 trial reported a median 30-month improvement in overall survival with $\mathrm{NC}$ in patients with T2-tumours, there is a strong rationale to use NC even in these patients. ${ }^{6,22}$

An alternate strategy is to use a risk-stratified approach, in which patients with high-risk features receive NC and lowrisk patients who are upstaged receive adjuvant chemotherapy (AC).$^{28}$ However, local expertise, experience with this approach and available diagnostic imaging and resources should be considered. It should be noted that less than a third of patients who were upstaged received AC - this is in line with data indicating that NC is more often successfully administered than AC (87\%-97\% vs. 50\%-77\%), ${ }^{4,29}$ perhaps because of postoperative complications, poor performance status and renal insufficiency. ${ }^{18,22,29,30}$ As those receiving AC had better disease-specific survival than those who did not, the inability to administer chemotherapy adjuvantly is a significant concern. ${ }^{28}$

Adoption of new treatment paradigms can be challenging. Even within this group of GU oncology specialists, $8 \%$ to $12 \%$ of clinicians do not offer NC - some expressed skepticism about the value of $\mathrm{NC}$ and were concerned about surgical delay in those not responding to NC. This has been cited as a reason for low NC uptake. ${ }^{17,24}$ The use of midtreatment staging to assess treatment response and to decide whether to continue NC or proceed to surgery, as well as the development of better predictors of chemosensitivity, may help alleviate these concerns and increase NC uptake.

This study has several limitations. As most respondents worked in academic centres and belonged to 2 professional societies focused on urologic cancers, our results may not 
be generalizable to the community setting where many bladder cancer cases are seen. Similarly the response rate for urologists was also low, which could also affect results. We acknowledge that the tumour substaging (e.g., T2a vs. T2b) used in our survey may not be useful clinically as this distinction may be difficult to discern preoperatively. Lastly, patient preference for immediate definitive therapy and/or to not receive chemotherapy was not accounted for in our study. ${ }^{13}$

\section{Conclusions}

To our knowledge, this is the first Canadian study of medical oncologists and urologists attempting to understand why $\mathrm{NC}$ use in MIBC is low. We found that most clinicians, who specialize in GU cancers and work in academic centers, do believe that NC is the standard of care for MIBC. Medical oncologists will offer NC to MIBC patients with adequate performance status, limited comorbidities and adequate renal function; however, these patients are not always referred prior to surgery. One potential approach to increase referral rate for NC may be to manage MIBC using a multidisciplinary approach. If lack of volume and experience are factors in the low uptake of $\mathrm{NC}$, consultation at a tertiary centre or discussion at a multidisciplinary tumour board may also be helpful.

Competing interests: Dr. Hsu, Dr. Eigl, Dr. North, Dr. Lau, Dr. Panzarella and Dr. Sridhar all declare no competing financial or personal interests. Dr. Black is a member of the advisory boards for Amgen, Janssen, Ferring and Astellas. He has also received a commercial grant from GenomeDx. He is currently participating in a clinical trial with Ferring, Astellas, GSK and Janssen. Dr. Chi has received a commercial grant from Astellas, Astra Zeneca, Amgen, Bayer, Janssen, Millenium, Novartis, Oncogenex and Sanofi. Dr. Canil has participated in Advisory Boards for Janssen, Pfizer, Astellas and Amgen. She has received speaking fees for Janseen and Astellas and travel grants from Novartis and Janssen. She has been an investigator in clinical trials for Pfizer, Janssen, Astellas and Sanofi Oncology. Dr. Kulkarni has received a commercial grant from Astellas and he is currently participating in a clinical trial with Spectrum Pharmaceuticals. Dr. Wood is a member of the advisory boards for Pfizer, Astellas and Janssen. She is also participating in clinical trials with GSK, BMS, Astellas and Novartis. Dr. Zlotta is a member of the advisory boards for Amgen, Ferring and Astellas. He has received commercial grants from Sanofi and Red Leaf Medical. He is also participating in a clinical trial with Sanofi Aventis.

This paper has been peer-reviewed.

\section{References}

1. Advisory committee on cancer statistics. Canadian cancer statistics 2013. Toronto, ON; Canadian cancer society; 2013.

2. Raghavan D, Shipley WU, Garnick MB, et al. Biology and management of bladder cancer. N Engl J Med 1990;322:1129-38. http://dx.doi.org/10.1056/NEJM199004193221607

3. Stein JP, Lieskovsky $G$, Cote $R$, et al. Radical cystectomy in the treatment of invasive bladder cancer: Long-term results in 1,054 patients. J Clin Oncol 2001;19:666-75.
4. Advanced Bladder Cancer Meta-analysis C. Neoadjuvant chemotherapy in invasive bladder cancer: Update of a systematic review and meta-analysis of individual patient data advanced bladder cancer (abc) metaanalysis collaboration. Eur Urol 2005;48: 202-5; discussion 205-6.

5. International Collaboration of Trialists 1; Medical Research Council Advanced Bladder Cancer Working Party (now the National Cancer Research Institute Bladder Cancer Clinical Studies Group); European Organisation for Research and Treatment of Cancer Genito-Urinary Tract Cancer Group; Australian Bladder Cancer Study Group; National Cancer Institute of Canada Clinical Trials Group; Finnbladder; Norwegian Bladder Cancer Study Group; Club Urologico Espanol de Tratamiento Oncologico Group, Griffiths G, Hall R, Sylvester R, Raghavan D, Parmar MK. International phase III trial assessing neoadiuvant cisplatin, methotrexate, and vinblastine chemotherapy for muscle-invasive bladder cancer: Long-term results of the ba06 30894 trial. J Clin Oncol 2011;29: 2171-7. http://dx.doi.org/10.1200/JC0.2010.32.3139

6. Grossman $H B$, Natale RB, Tangen $C M$, et al. Neoadjuvant chemotherapy plus cystectomy compared with cystectomy alone for locally advanced bladder cancer. N Engl J Med 2003;349:859-66. http://dx.doi. org/10.1056/NEJMoa022148

7. Booth $C M$, Siemens $D R$, Li G, et al. Perioperative chemotherapy for muscle-invasive bladder cancer: $A$ population-based outcomes study. Cancer 2014;120:1630-8. http://dx.doi.org/10.1002/cncr.28510

8. Reardon $Z D$, Patel $S G$, Zaid HB, et al. Trends in the use of perioperative chemotherapy for localized and locally advanced muscle-invasive bladder cancer: A sign of changing tides. Eur Urol 2014. http://dx.doi. org/10.1016/j.eururo.2014.01.009

9. Liew MS, Azad A, Tafreshi A, et al. USANZ: Time-trends in use and impact on outcomes of perioperative chemotherapy in patients treated with radical cystectomy for urothelial bladder cancer. BJU Int 2013;112(Suppl 2):74-82. http://dx.doi.org/10.1111/bju.12384

10. Oken MM, Creech RH, Tormey DC, et al. Toxicity and response criteria of the eastern cooperative oncology group. Am J Clin Oncol 1982;5:649-55. http://dx.doi.org/10.1097/00000421-198212000-00014

11. El-Gehani F, North $S$, Ghosh $S$, et al. Improving the outcome of patients with muscle invasive urothelial carcinoma of the bladder with neoadjuvant gemcitabine/cisplatin chemotherapy: A single institution experience. Can Urol Assoc J 2014;8:e287-93. http://dx.doi.org/10.5489/cuaj.1643

12. Miles BJ, Fairey AS, Eliasziw M, et al. Referral and treatment rates of neoadiuvant chemotherapy in muscle-invasive bladder cancer before and after publication of a clinical practice guideline. Can Urol Assoc J 2010;4:263-7. http://dx.doi.org/10.5489/cuaj09134

13. Rehman $S$, Crane $A$, Din $R$, et al. Understanding avoidance, refusal, and abandonment of chemotherapy before and after cystectomy for bladder cancer. Urology 2013;82:1370-5. http://dx.doi.org/10.1016/i. urology.2013.07.055

14. Seah JA, Blais N, North S, et al. Neoadjuvant chemotherapy should be administered to fit patients with newly diagnosed, potentially resectable muscle-invasive urothelial cancer of the bladder (mibc): A 2013 cagmo consensus statement and call for a streamlined referral process. Can Urol Assoc J 2013;7:312-8. http://dx.doi.org/10.5489/cuaj.1506

15. Canter D, Viterbo R, Kutikov A, et al. Baseline renal function status limits patient eligibility to receive perioperative chemotherapy for invasive bladder cancer and is minimally affected by radical cystectomy. Urology 2011;77:160-5. htrp://dx.doi.org/10.1016/j.urology.2010.03.091

16. Meeks JJ, Bellmunt J, Bochner BH, et al. A systematic review of neoadjuvant and adjuvant chemotherapy for muscle-invasive bladder cancer. Eur Urol 2012;62:523-33. http://dx.doi.org/10.1016/j. eururo.2012.05.048

17. Feifer AH, Taylor JM, Tarin TV, et al. Maximizing cure for muscle-invasive bladder cancer: Integration of surgery and chemotherapy. Eur Urol 2011;59:978-84. http://dx.doi.org/10.1016/j.eururo.2011.01.014

18. Dash A, Galsky MD, Vickers AJ, et al. Impact of renal impairment on eligibility for adjuvant cisplatin-based chemotherapy in patients with urothelial carcinoma of the bladder. Cancer 2006;107:506-13. http:// dx.doi.org/10.1002/cncr.22031

19. Extermann M. Measurement and impact of comorbidity in older cancer patients. Crit Rev Oncol Hematol 2000;35:181-200. http://dx.doi.org/10.1016/S1040-8428(00)00090-1

20. Chau CSY, Wheater MJ, Geldart TR, et al. Comparison of cisplatin-based neoadjuvant chemotherapy for bladder cancer in elderly versus younger patients. ASCO Meeting Abstracts 2014;32:e15502. http:// meeting.ascopubs.org/cgi/content/abstract/32/15_suppl/e15502. Accessed October 6, 2014.

21. Boustead GB, Fowler S, Swamy R, et al. Stage, grade and pathological characteristics of bladder cancer in the uk: British association of urological surgeons (baus) urological tumour registry. BJU Int 2013;113:924-30

22. Herr HW, Dotan Z, Donat SM, et al. Defining optimal therapy for muscle invasive bladder cancer. J Urol 2007;177:437-43. http://dx.doi.org/10.1016/i.juro.2006.09.027

23. SEER Cancer Statistics Review. Median Age of Cancer Patients at Diagnosis by Primary Cancer Site, Race, and Sex, 2005-2009. http://www.seer.cancer.gov/csr/1975_2009_pops09/results_single/ sect_01 table.11_2pgs.pdf. Accessed September 15, 2014.

24. Black $P, S_{0}$ A. Perioperative chemotherapy for muscle-invasive bladder cancer. Can Urol Assoc J 2009:3:S223-7. 
Hsu et al.

25. Svatek RS, Shariat SF, Novara G, et al. Discrepancy between clinical and pathological stage: External validation of the impact on prognosis in an international radical cystectomy cohort. BJU Int 2011;107:898904. http://dx.doi.org/10.1111/i.1464-410X.2010.09628.x

26. Gray PJ, Lin CC, Jemal A, et al. Clinical-pathologic stage discrepancy in bladder cancer patients treated with radical cystectomy: Results from the national cancer data base. Int J Radiat Oncol Biol Phys 2014;88:104856. http://dx.doi.org/10.1016/i.i.jobp.2014.01.001

27. Turker P, Bostrom PJ, Wroclawski ML, et al. Upstaging of urothelial cancer at the time of radical cystectomy: Factors associated with upstaging and its effect on outcome. BJU Int 2012;110:804-11. http://dx.doi. org/10.1111/i.1464-410X.2012.10939.x

28. Culp SH, Dickstein RJ, Grossman HB, et al. Refining patient selection for neoadjuvant chemotherapy before radical cystectomy. J Urol 2014;191:40-7. http://dx.doi.org/10.1016/i.juro.2013.07.061
29. Millikan R, Dinney C, Swanson D, et al. Integrated therapy for locally advanced bladder cancer: Final report of a randomized trial of cystectomy plus adjuvant m-vac versus cystectomy with both preoperative and postoperative m-vac. J Clin Oncol 2001;19:4005-13.

30. Donat SM, Shabsigh A, Savage C, et al. Potential impact of postoperative early complications on the timing of adjuvant chemotherapy in patients undergoing radical cystectomy: A high-volume tertiary cancer center experience. Eur Urol 2009;55:177-85. http://dx.doi.org/10.1016/i.eururo.2008.07.018

Correspondence: Dr. Srikala S. Sridhar, Medical Oncologist, Princess Margaret Hospital, Assistant Professor, University of Toronto, Toronto, ON M5G 2M9; srikala.sridhar@uhn.ca 